\title{
Sequence of Tissue Responses in the Early Stages of Experimental Allergic Encephalomyelitis (EAE): Immunohistochemical, Light Microscopic, and Ultrastructural Observations in the Spinal Cord
}

\author{
FERNANDO E. D'AMELIO,,$^{3}$ MARION E. SMITH, ${ }^{2}$ AND LAWRENCE F. ENG ${ }^{1}$ \\ ${ }^{1}$ Departments of 'Pathology' and ${ }^{2}$ Neurology, Stanford University School of Medicine, Stanford, California \\ 94305. 1,2Veterans Administration Medical Center, Palo Alto, California 94304; ${ }^{3}$ Life Science Ditision, \\ NASA-Ames Research Center, Moffett Field, California 94035
}

KEY WORDS Morphological change, Glial filaments, Inflammatory cells

ABSTRACT Experimental allergic encephalomyelitis (EAE) was induced in adult Lewis rats with purified guinea pig CNS myelin and Freund's adjuvant. As soon as the very earliest clinical signs appeared the animals were perfused with fixatives and the spinal cord analyzed by electron microscopy, silver methods, and immunocytochemistry.

Our findings suggest that in the early stages of EAE a sequence of events can be traced, although these events frequently overlap. The earliest morphological change appears to be astrocytic edema in both the cell body and processes. Increased amounts of glycogen particles and dispersion of glial filaments are prominent. These changes seem to occur just prior to the time when inflammatory cells begin to penetrate the capillary walls. Invasion of the neuropil mainly by macrophages and lymphocytes closely follows. Both macrophages and microglia seem to participate in phagocytosis of oligodendrocytes and myelin. Demyelination, however, is not a prominent feature at this early stage.

\section{INTRODUCTION}

In a previous publication we examined the alterations of glial fibrillary acidic protein (GFAP) in astrocytes and the accompanying ultrastructural modifications at the onset of EAE (Eng et al., 1989). Since previous investigations by Smith et al. (1983) confirmed later by Aquino et al. $(1988 \mathrm{a}, \mathrm{b})$ have shown that GFAP content did not increase during the first 13-18 days of development of EAE, we suggested that the increase in GFAP immunoreactivity observed by us was due to the exposure of more antigenic sites against GFAP brought about by the dissociation and dispersion of glial filaments within the edematous astrocytic cytoplasm and processes. In this report we suggest a sequence of tissue responses that take place during the course of the early stages of EAE.

\section{MATERIAL AND METHODS Animals}

Adult male Lewis rats, about $250-300 \mathrm{~g}$ (purchased from Charles River, Wilmington, MA), were employed in this study.

\section{Immunization Procedures}

On day 0 the rats were injected in the flanks of both hind legs with a total of $1 \mathrm{mg}$ lyophilized purified guinea

\footnotetext{
Received November 8, 1989; accepted March 10, 1990.

Address reprint requests to Laurence F. Eng. Patholog. Research 1151B. Address reprint requests to Lawrence F. Eng, Patholog Avenue. Palo A to. California 94304
} 

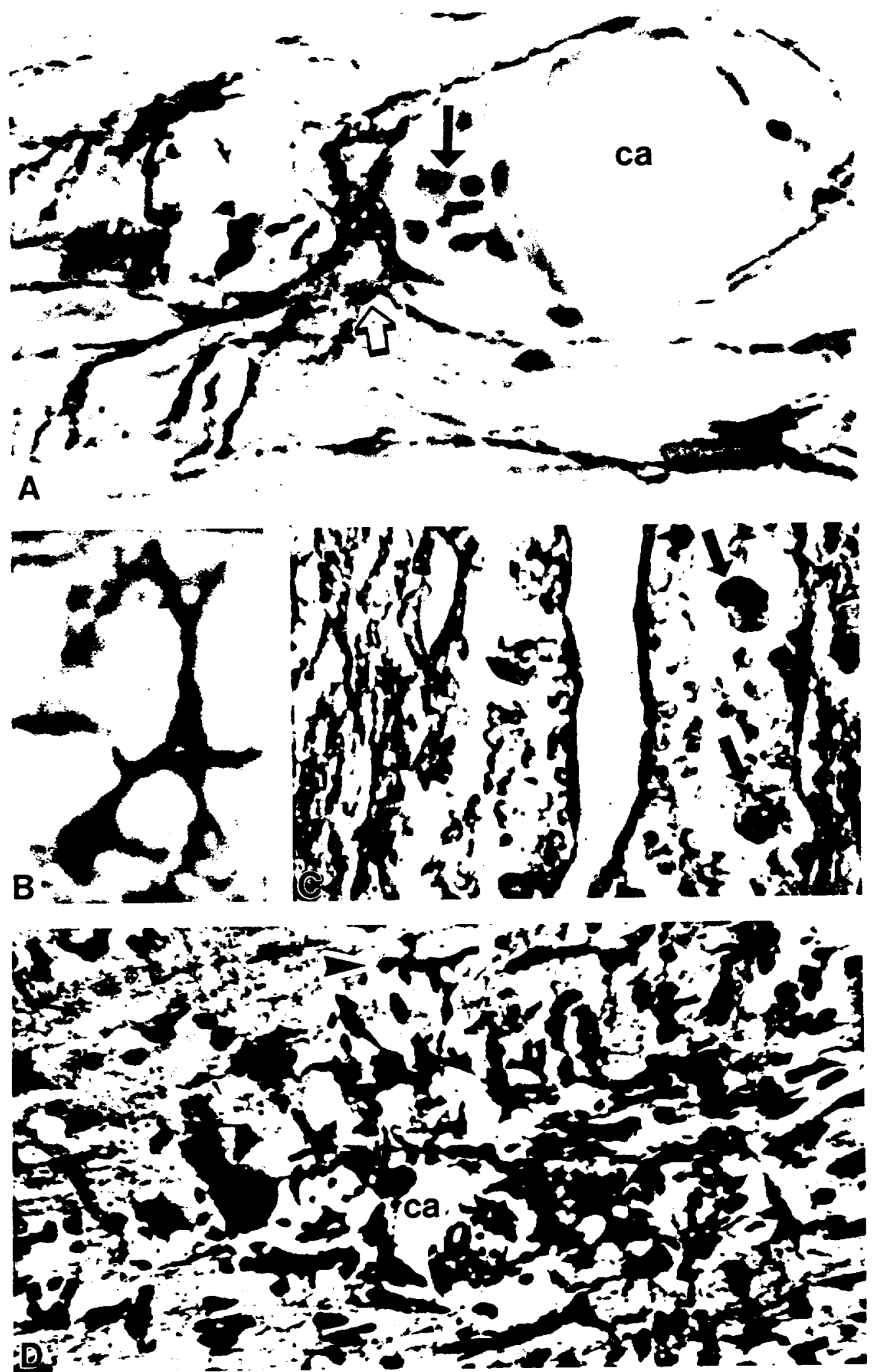

Fig. 1. EAE, lumbar spinal cord. A: Hypertrophic and intensely GFA -immunoreactive perivascular astrocyte (Andriezen type, open arrow) in the white matter abuts upon the basement membrane of a arrow) in the white inflammatory infiltrate of "mononuclear" cells has capillary (ca). An inflammatory inse (arrow, compare with Fig. 5). dissected the basement membrane (arrow, compare with Fig. Section immunostained for GFAP (Sterimal Very small, "star"-shaped stained with hematoxilin. B. microglial cell, typical of the white matter of the spinal cord. Silver method for microglial cells. C: Longitudinal section of a blood vessel multinucleated macrophages (arrow). The MBP-immunoreactive fibers have counterstained with cresyl violet. D: En masse macrophagic invasion of the neuropil. The macrophages show various sizes and shapes; some of them are seen in juxtavascular location arround a capillary (ca), suggesting monocytic and/or pericytal origin; and others, in the neuropil, are suggestive of reactive microgliocytes (arrowhead). Silver method, appropriate for the impregnation of macrophages, microglial mells a d ricytes. A, ×536; B $\times 2,430 ; C, \times 800 ; D, \times 400$. 

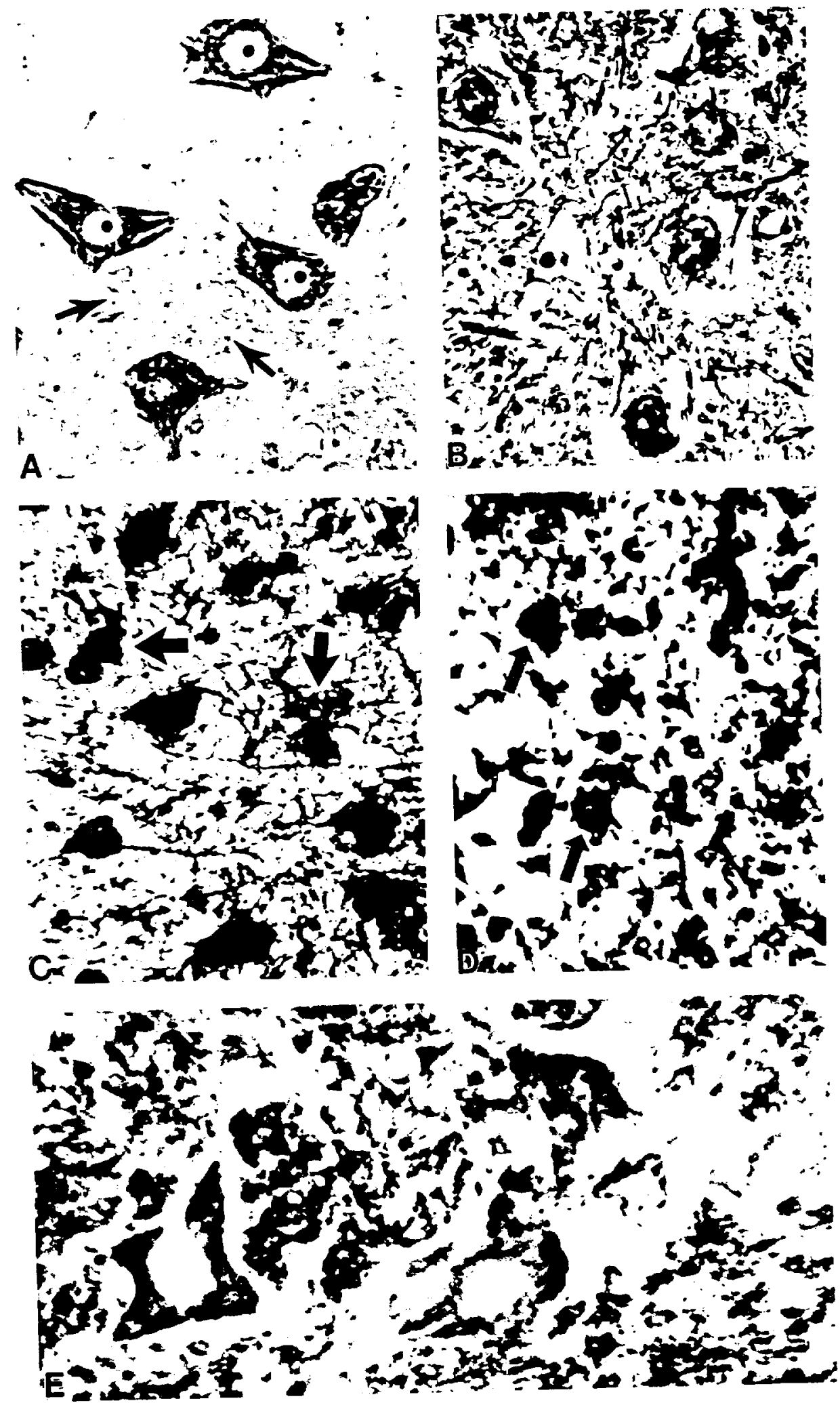

Fig. 2. EAE, lumbar spinal cord. A: Control animal. Motoneurons are surrounded by myelinated fibers (arrows) faintly stained with are surrounded by mentimal. Motoneurons surrounded by a mesh of anti-MBP. B: Control animal. Motoneurons surrounded by a mesh of nerve fibers. C: Shrunken motons reveal severe structural deteriora$\mathrm{EAE}$ animal. Some of the neurons reveal severe structural detiosis is tion (arrows). In the center of the photograph a marked fibrogliosis is apparent. "Triple" silver impregnation method counterstained with gold chloride. D: Area of the gray matter invaded by phagocytic cells, somefthem multinucleated (arrows) Silver impregnation method for some of them multinucleated (arros. macrophages and microglia. E: Motoneurons with The ne cells are fuse basophilia and severe degenerative changes. The nerve cells are surrounded by nerve fibers in the process of desintegration of their myelin sheaths. Section immunostained for MBP and counterstained with cresyl violet. C-E: Photographs belong to sections taken from one animal in the same area

D. $\times 2,300 ; \mathrm{E}, \times 1.000$ 
pig CNS myelin in $0.25 \mathrm{ml}$ Freund's complete adjuvant (Difco, Detroit, MI) to which was added $3 \mathrm{mg} / \mathrm{ml} M y c o$ bacterium tuberculosis H37Ra (Difco). When the first clinical signs of EAE became apparent (weight loss and tremor; $10-12$ days) the rats were anesthetized with methoxyflurane and processed for immunohistochemical and structural studies as described below.

Control rats (FAC) were injected with Freund's adjuvant containing H37Ra Mycobacterium tuberculosis alone (Smith et al., 1983) and were processed together with the EAE rats.

\section{Light Microscopic Procedures}

Immunohistochemistry

The rats were perfused with $4 \%$ paraformaldehyde in $0.12 \mathrm{M}$ phosphate buffer, $\mathrm{pH} 7.4$. Longitudinal samples of the spinal cord were infiltrated with paraffin according to standard procedures and sectioned at $10 \mu \mathrm{m}$ thickness. They were subsequently treated with antibodies to GFAP (Eng and Rubinstein, 1978) or myelin basic protein (MBP) and immunostained according to the peroxidase-antiperoxidase method developed by Sternberger (1986). Counterstaining with cresyl violet or hematoxylin was applied on some of the sections.

\section{Silver impregnation techniques}

The animals were perfused with $4 \%$ paraformaldehyde in distilled water containing $2 \%$ ammonium bromide. Samples of the spinal cord were cut with a freezing microtome at $20-30 \mu \mathrm{m}$ thickness and were processed for the visualization of macrophages/microglial cells, neuroglial components or neurons according to the methods originally developed by del Rio Hortega and described elsewhere (D'Amelio, 1981).

In some instances, for comparative purposes, the same sample of spinal cord of individual animals was used for both silver impregnation techniques and immunocytochemical procedures (MBP and GFAP).

\section{Electron Microscopic Procedures}

The rats were perfused with $1 \%$ paraformaldehyde and $1.5 \%$ glutaraldehyde in $0.12 \mathrm{M}$ phosphate buffer, $\mathrm{pH}$ 7.4. The samples were postfixed in $2 \%$ osmium tetroxide in phosphate buffer at $\mathrm{pH} 7.4$, dehydrated by standard methods, and embedded in Quetol 651 epoxy resin. The blocks were sectioned at $600 \AA$, stained with uranyl acetate-lead citrate, mounted on copper grids, and observed in a Philips 300 electron microscope.

\section{RESULTS}

The description of our observations reflect the sequence of events that we believe take place during the early stages of $\mathrm{EAE}$.

\section{Astrocytic Alterations}

The main changes found in the astrocytic population were described in a previous publication (Eng et al., 1989). Briefly, light microscopic preparations immunostained with anti-GFAP revealed hypertrophy of astrocytes and increased immunoreactivity for GFAP (Fig. 1A). These characteristics were also obvious in the gray matter that exhibited a marked proliferation of glial fibers visible in between the motoneurons (Fig. $2 \mathrm{C}$ ). Distinctive ultrastructural features of astrocytes were a considerable "watery" swelling of cytoplasm and processes accompanied by widespread dispersion of the glial filaments and increased amounts of glycogen particles (Fig. 3A). These changes involved the most slender astrocytic extensions including the foot processes impinging upon the walls of blood vessels and capillaries. The latter appeared frequently without obvious morphological alterations (Fig. 4). In addition to these changes some areas showed what appeared to be glial filaments forming tight bundles, intensely osmiophilic, somewhat reminiscent of Rosenthal fibers (Fig. 3B,C).

\section{Inflammatory Infiltrates}

The inflammatory reaction showed perivascular and diffuse patterns. The perivascular inflammatory cuffs were mainly composed of lymphocytes and macrophages that in both light microscopic and ultrastructural images appeared to dissect the vascular walls in between the endothelium and basement membrane (Fig. 1A,C, 5, 6). When stained with silver impregnation methods the macrophages, seen in perivascular situation or independent of vascular structures, showed a broad range of morphological variations such as large multinucleated elements, cells with ameboid features, rod-shaped components, and others with characteristics reminiscent of reactive microglial cells (Fig. 1D). These cells were also seen in some areas of the gray matter lying among neuronal elements, which showed profound alterations that included increased and diffuse cytoplasmic basophilia, irregularity of cell contours, retraction of soma and processes, increased metalophilia of the filamentous components, and complete loss of structure (Fig. 2C,D,E). On occasion, macrophages and cells identified as activated microglia were seen in the neuropil enclosing oligodendrocytes and myelin sheaths or containing cellular debris (Fig. 7). In other instances, perivascular microglial cells surrounded by astrocytic expansions appeared to become detached from the vascular walls as if derived from pericytic precursors (Barón and Gallego, 1972) (see Fig. 5).

\section{Myelin Alterations}

Demyelination was not a prominent feature at this stage of development of EAE, although some myelin breakdown was revealed in light microscopic images by 


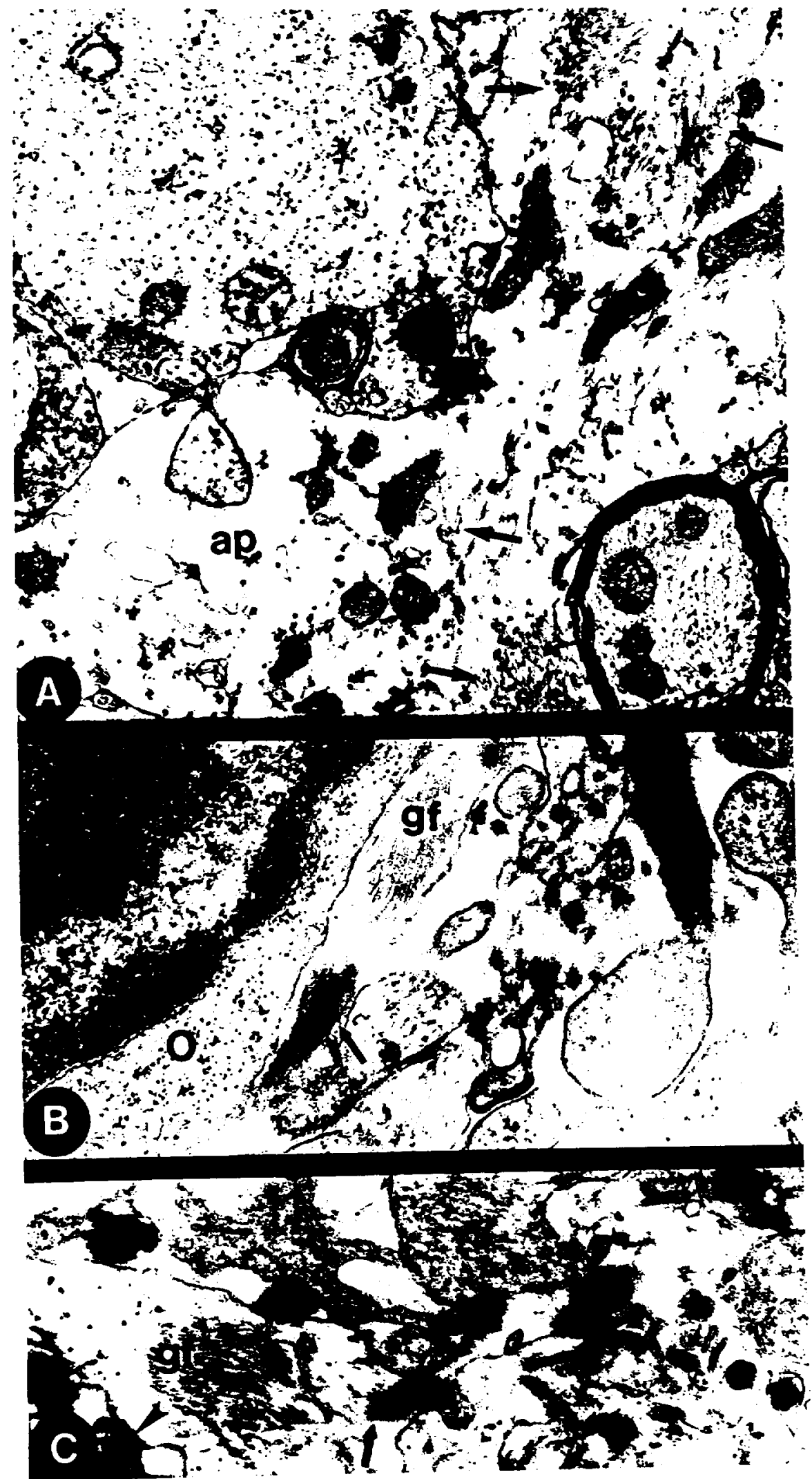

Fig. 3. EAE, lumbar spinal cord. A: Markedly swollen astrocytic process (ap) containing dispersed and dissociated glial filaments (arrows) Particulate glycogen is also apparent. B: Astrocytic expanarrows). Particulate filaments (gf) and sion adjacent to an oligodendrocyte (i) coted as tight bundles of glial filaments somewhat reminiscent of Rosenthal fibers (arrow) C. An astrocytic process that shows a gap junction (arrowheadi displays both alial The intracellular gial filaments and $\mathrm{Osm} \times 25,650 ; \mathrm{B}, \mathrm{C}, \times 31,250$ 


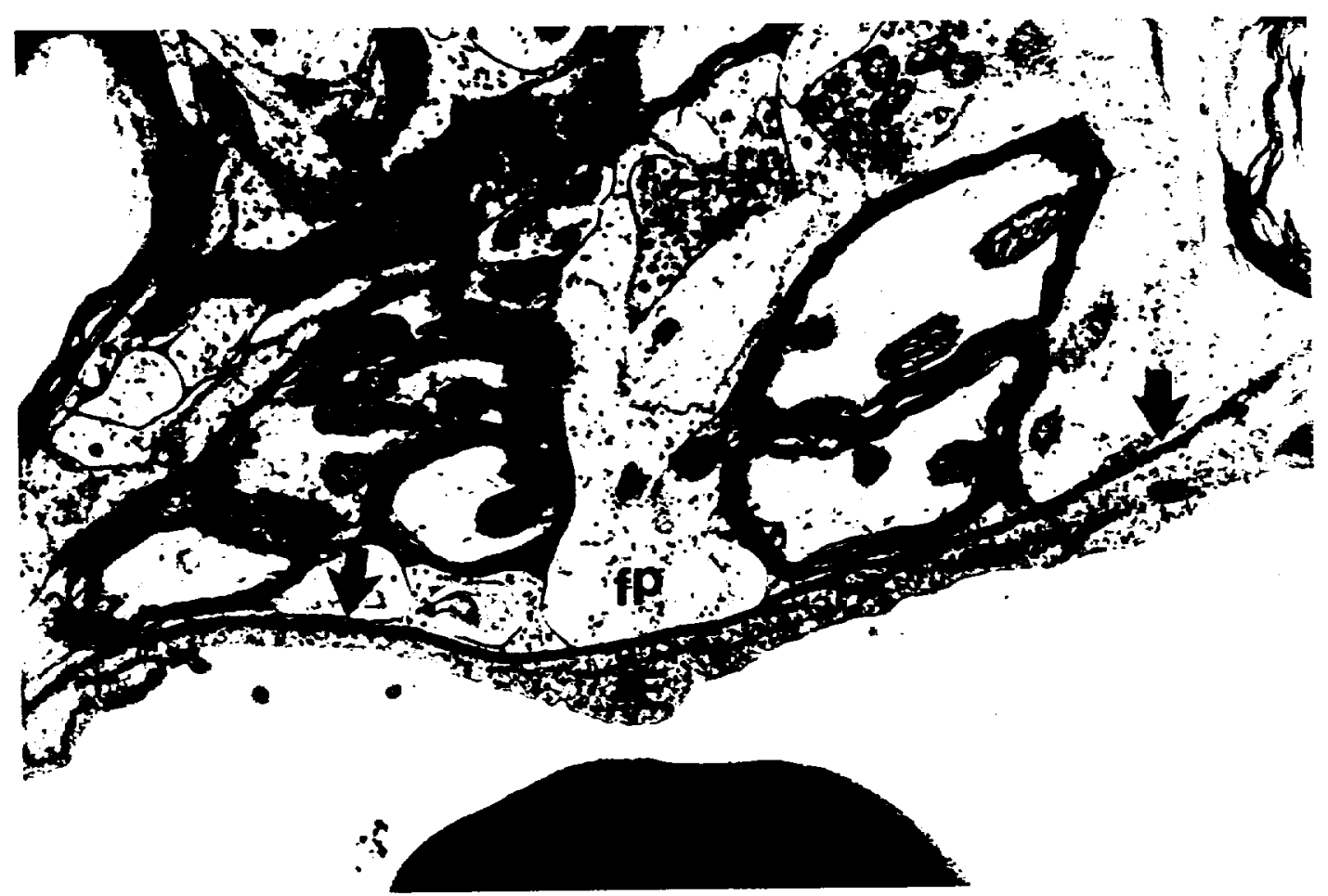

Fig. 4. EAE, lumbar spinal cord. Swollen astrocytic foot processes ( $f p$ ) containing glycogen particles abutting upon the intact basement membrane of a capillary (arrows). E, cytoplasmic expansion of an endothelial cell; $\mathrm{RBC}$, red blood cell. $\times 14,175$.

means of antiserum against myelin basic protein (MBP) and by electron microscopy. The areas of myelin disruption, as seen in light microscopic images, were frequently accompanied by macrophagic invasion and showed proliferation of glial fibers. This picture was particularly evident, for example, in the myelinated fibers traversing areas of the gray matter in which the neuronal lesions were more intense (Fig. $2 \mathrm{E}$ ). In ultrastructural images it was possible to observe regions with denuded normal axons occasionally surrounded by densely osmiophilic material (Fig. 8).

\section{DISCUSSION}

The immunohistochemical and morphological examination of the spinal cord in the early stages of EAE revealed lesions in various phases of development that overlap among and within the experimental animals. One of those phases involve the observations made in our first study (Eng et al., 1989). We then suggested that the increase in blood-brain barrier (BBB) permeability was responsible for the astrocytic edema with the resulting dissociation and dispersion of the glial filaments. The transport of fluid (mainly water and electrolytes) without visible damage to the walls of capillaries and blood vessels may be due to a "partial" breakdown of the BBB (see Lee, 1982; Miquel et al., 1982) elicited by the antigenic agression. Whether fluid extravasation precedes or is simultaneous with mononuclear cell invasion through the vascular walls cannot be thoroughly assessed in this study. However, the electron lucency and the lack of proteinaceous material in the astrocytic edema lead us to conclude that the first assumption is more tenable. Furthermore, quantitative determinations of BBB permeability and histological analysis during the course of EAE in Lewis rats showed that BBB permeability preceded the appearance of perivascular cellular infiltrates (Juhler et al., 1984). The finding of other morphological indicators of metabolic disturbances in the astroglial cytoplasm such as the presence of what appears to be the arrangement of glial filaments in tight, osmiophilic bundles, may represent a subsequent reactive response of astrocytes to the overloading with edema fluid. Although the first observations of these bodies suggested to us that they might represent fibrin, the fact that they are frequently seen occupying the same space as glial filaments or lying close to them speak in favor of their intracellular location (see Fig. $3 B, C)$. Thus, it appears reasonable to correlate the structural changes of astroglia with the increased permeability of the vascular walls. Astroglial alterations would in turn play a significant role in the further disruption of the BBB and hence in the facilitation of cellular migration of inflammatory components toward the neuropil. 


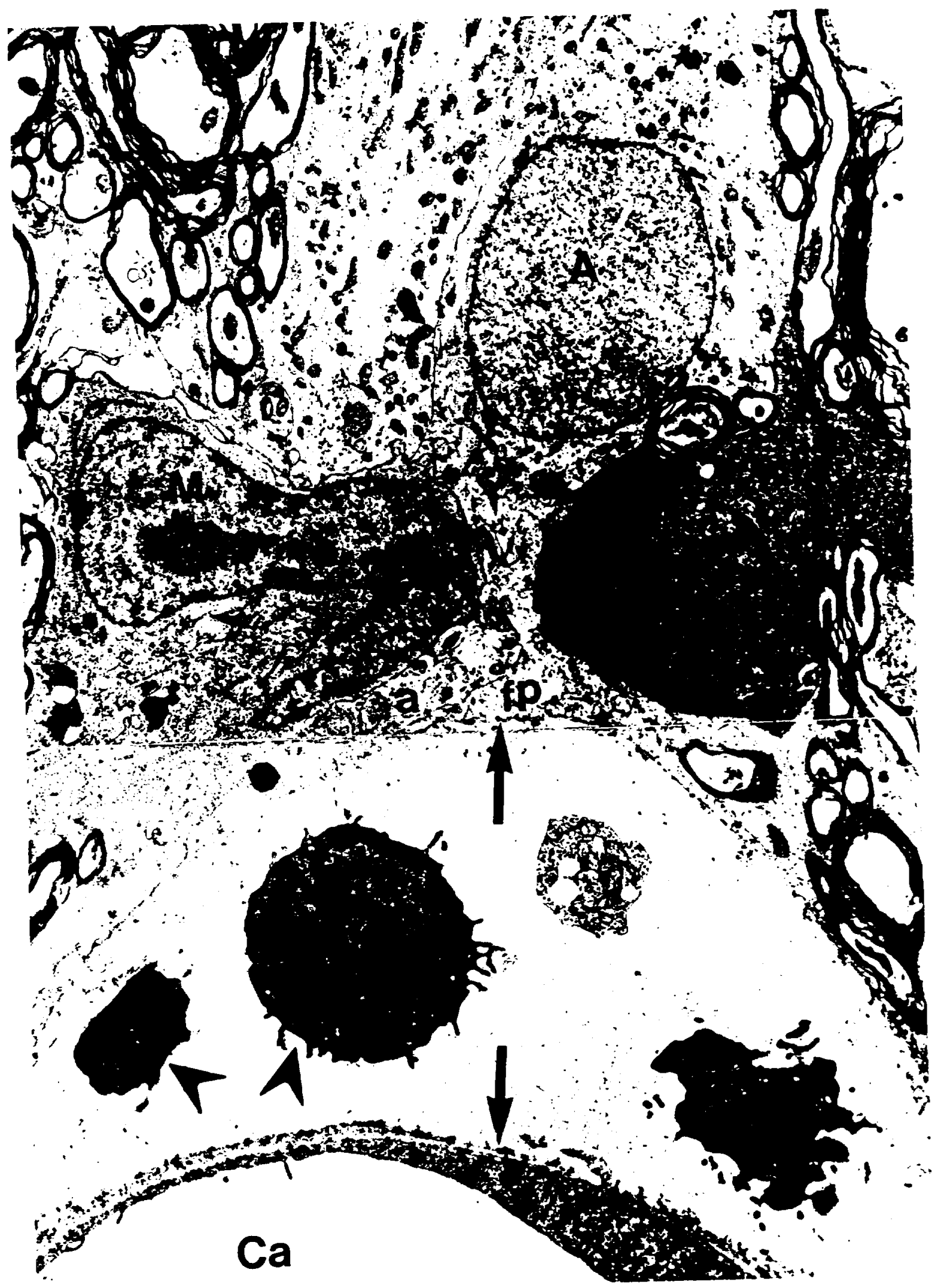

Fig. 5. EAE, lumbar spinal cord. Lymphocytes (arrowheads) and Fig. 5. EAE, lumbar spinalls have broken through the basement fragments of unidentified cells have broken through the basems (fp) of membrane (arrows) of a capillary (ca). The swollen foot process (fp) of an astrocyte $(A)$ containing glycogen particles impinges upon the

in close apposition to normal axons. A perivascular microglial cell $1 M$ I $/$ is in close appillary by an astrocytic expansion (a), suggesting a pericytic origin. $E$. endothelial cell nucleus. $\times 5,600$ 


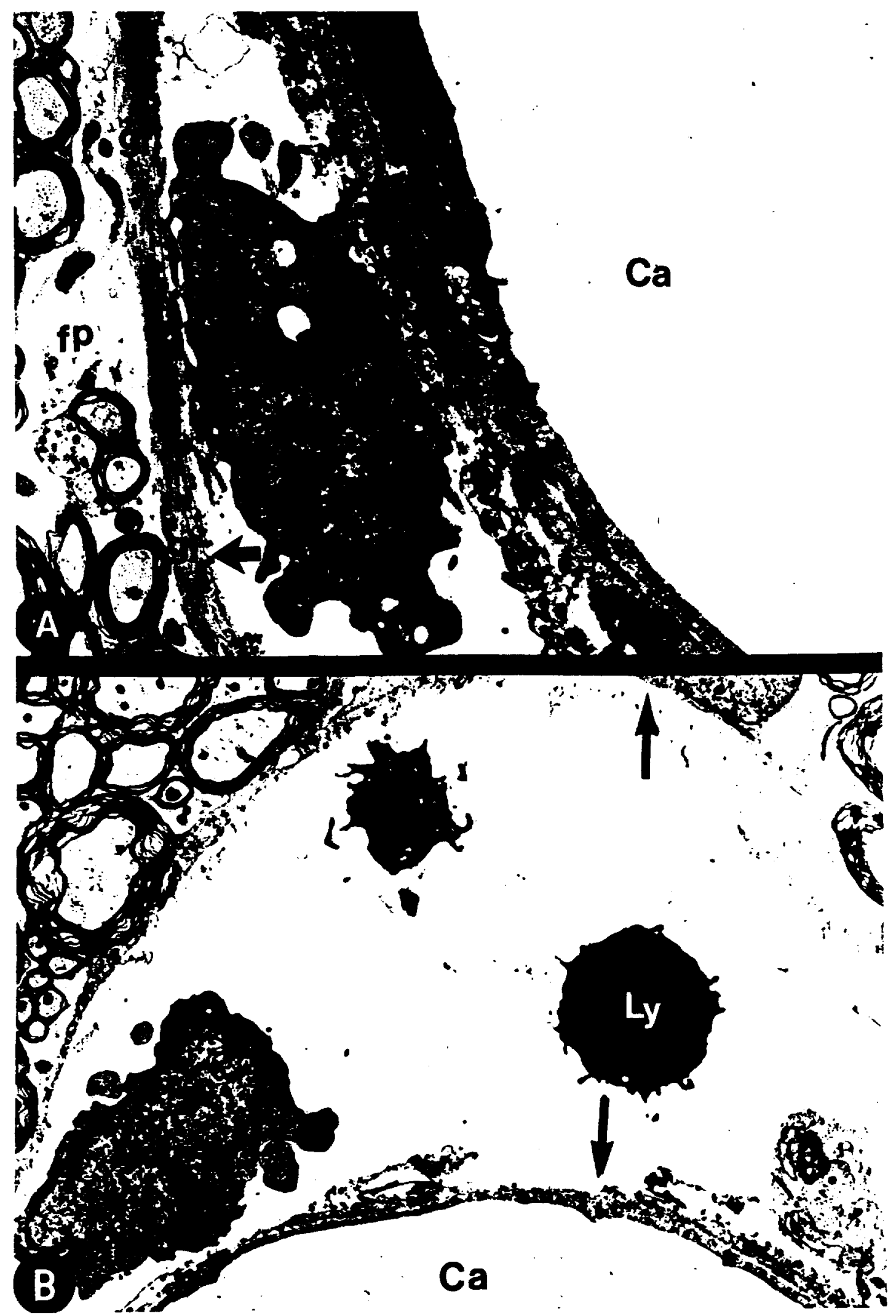

Fif 6. EAE lumbar spinal cord. A: A macrophage has "dissected" the basement membrane of a capillary (ca). B: Perivascular lymphocyte (Ly) and "mononuclear" cell (macrophage?) (Ma). The cells have broken through the basement membrane (arrows) of a capillary (ca) that is surrounded by some normal myelinated axons and some with irregular swelling of the myelin lamellae. $A, \times 11,990 ; B, \times 5,600$. 


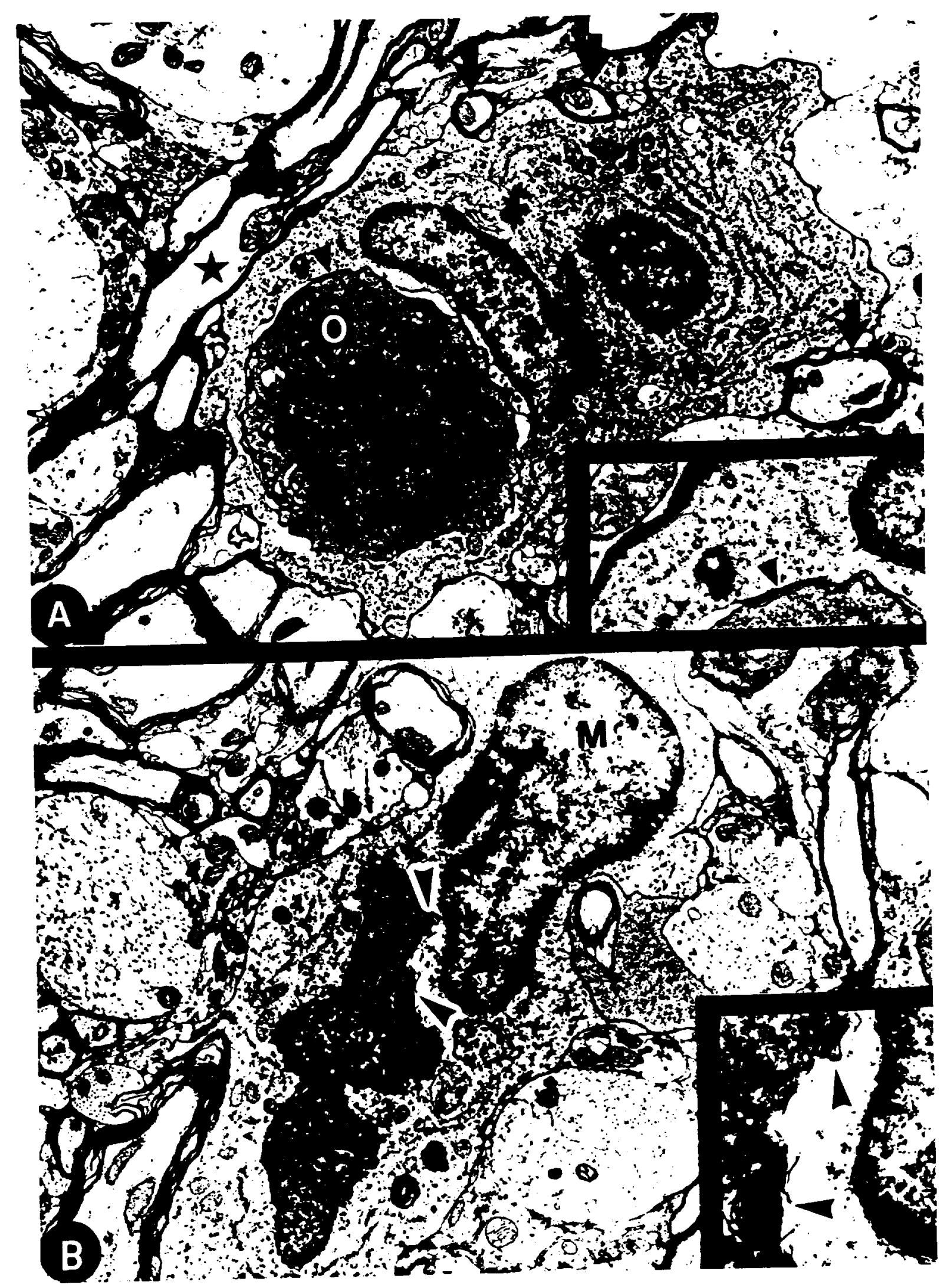

Fig 7. EAE lumbar spinal cord. A: A phagocytic cell is seen comFig. 7. EAE pletely enveloping another cell with a bilobed nucle myelinated axons oligodendrocyte $(0)$ and also closely apposed to myelinated axons (arrows). The process of the macrophage adjacent to an axon oriented longitudinally (star) appears to dissect the myelin sheath of the latter.

cytoplasmic membrane of the oligodendrocite (triangle, inset). B: cytoplasm occupied bv a prominent Microglial cell (M) with a large cytoplartially digested cell (oligodenphagosome, which is interpreted as a partialy digested cell drocyte?). Adjoining the phagosome there are lamelated myelin bodie $\times 7,970$; inset, $\times 20,250$. 


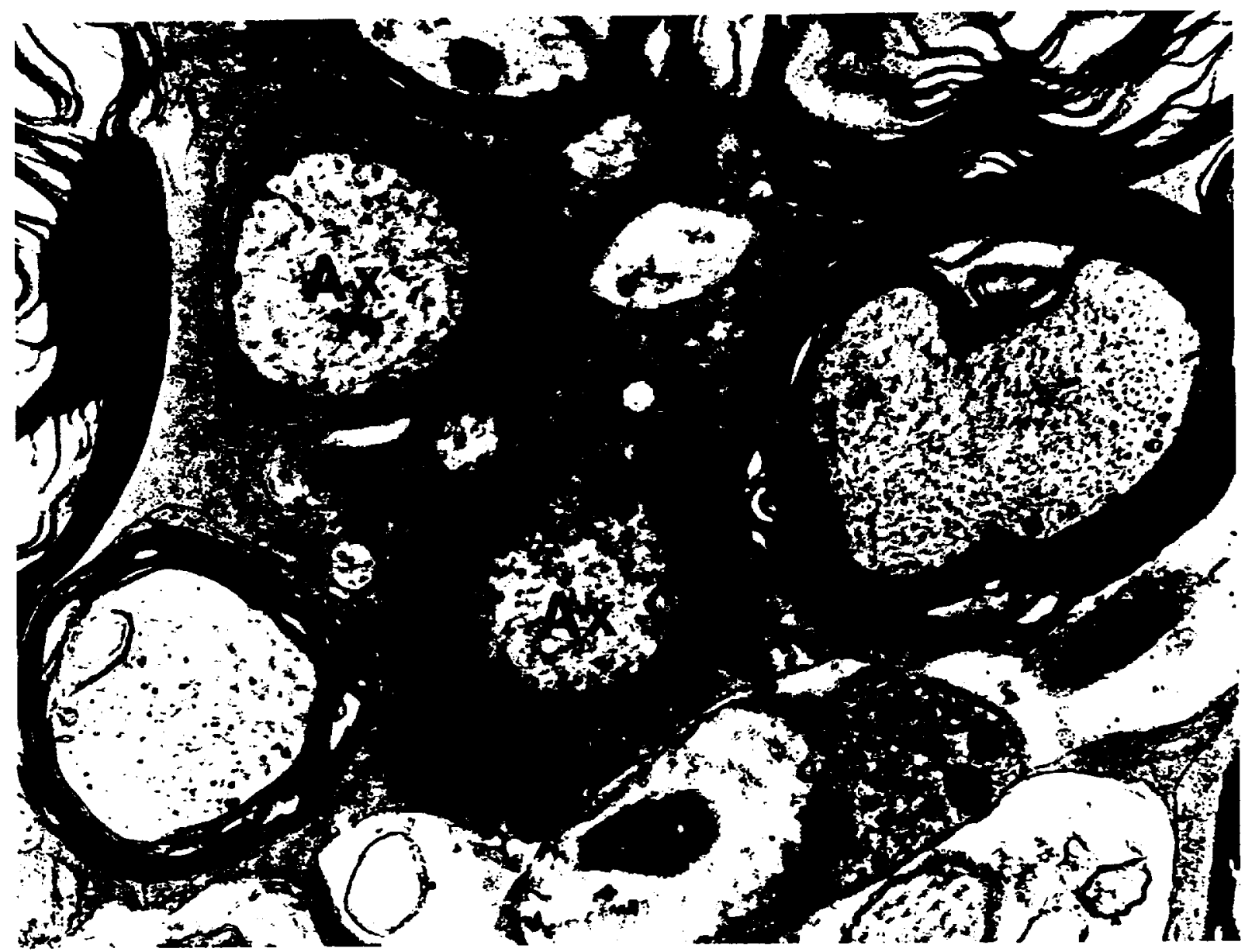

Fig. 8. EAE, lumbar spinal cord. Naked axons (Ax) are surrounded by osmiophilic material and by other axons with irregular swelling of the myelin lamellae. The axon in the upper left corner still retains a vestige of its myelin sheath. $\times 21,875$.

As brought out in our description, the dominant component of the cellular infiltrates are macrophages which can be found both in the perivascular regions and in the neuropil. The designation of "macrophage" refers to the morphological appearance of a cell endowed with phagocytic activity and does not assume any specific cell source. Different origins such as monocytes, pericytes, and microgliocytes have been proposed in the past (Rio Hortega, 1932; Cancilla et al., 1972; Oehmichen, 1975; Imamoto and Leblond, 1978; Polak et al., 1982). In our opinion it is conceivable that these cell types might be complementary in function and band together in response to the antigenic insult. In some instances, however, it is possible to discriminate between a microglial cell with phagocytic activity and a macrophage of indeterminate origin. Microglial cells usually display some distinctive features such as an elongated nucleus with "patchy" peripheral condensation of the chromatin, sparse single and narrow strands of endoplasmic reticulum, and presence of osmiophilic dense bodies (Polak et al., 1982) (see Fig. 7). Recent studies have demonstrated the microglial nature of proliferating macro- phages (Graeber et al., 1988; Streit and Kreutzberg, 1988; see also Streit et al., 1988). These modern investigations support the original contention by del Rio Hortega, who was the first to trace the evolution of changes sustained by microglial cells on their way to macrophage transformation (Rio Hortega, 1932). In an earlier radioautographic study of $\mathrm{EAE}$ in the rat (Kosunen et al., 1963), it has been suggested that the mononuclear cells of the perivascular infiltrates divide one or more times during the process of migration to the neuropil, where they take on the morphology of activated microglia. Moreover, microglial cell-derived macrophages can act as antigen presenting cells (APC) as they bear Ia antigens, which would enhance lymphocyte (T cells) recruitment (Fontana et al., 1987; Streit et al., 1988; see also Konno et al., 1989). In this way activated $\mathrm{T}$ cells would be able to secrete factors such as interferon- $\gamma$ (INF- $\gamma$ ) and contribute to the promotion of macrophagic activity involved in tissue injury (Fontana et al., 1987; Sobel et al., 1987). In this connection, Trotter and Smith (1984) have suggested that in cellmediated demyelinating diseases myelin phagocytosis 
may be initiated by an antibody bridge between the myelin sheath and the Fc receptor of the phagocytic cell (see also, Smith et al., 1989). A functional cooperation between microglial cells and astrocytes was suggested by Konno et al. (1989), who found clusters of Ia-immunoreactive microglial cells surrounded by astrocytes with increased GFAP-immunoreactivity in the gray matter of spinal cord of EAE Lewis rats.

Myelin breakdown or demyelination, although not dominant features in our observations at this early stage, were more easily visualized in the myelinated fibers running along some circumscribed regions of the gray matter than in the white matter. The difference in MBP immunoreactivity between the control animals (slight) and the EAE animals (very intense) is most likely due to the exposure of more epitopes at the onset of myelin breakdown. These regions of the gray matter contained abnormal neurons with alterations comparable to those described in the motoneurons of the mouse after axotomy (Lison, 1962; see also Cragg, 1970) and were spatially related to the invading phagocytic cells. In this connection it is interesting to note that in acute EAE Lewis rats, Konno et al. (1989) observed large numbers of Ia-immunoreactive microglial cells concomitant with extensive degeneration of axon terminals in the gray matter of the spinal cord where microglial cells are by far more numerous than in the white matter (Rio Hortega, 1921). We share the view that the appearance of demyelinated fields is directly related to phagocytic activity targeting both oligodendrocytes and myelin sheaths. Phagocytosis of oligodendrocytes has been observed at later stages (14-16 days) of EAE (Field and Raine, 1966). It has also been documented that the severity of demyelination differs according to the animal species (see Roizin et al., 1982, for review).

In conclusion, we believe that the pathogenesis of the early stages of EAE involve the following events: 1) edema induced by partial breakdown of BBB that affect predominantly astrocytes which exhibit increased GFAP immunoreactivity due to dissociation of glial filaments and consequent exposure of more antigenic sites; 2 ) as a consequence of further disruption of the $\mathrm{BBB}$, "activated" lymphocytes and blood-borne macrophages penetrate the vascular endothelium "en route" to the neuropil; 3) myelin breakdown is initiated by macrophagic activity upon oligodendroglia and myelin sheaths. Sources of macrophages in the tissue are considered to be multiple (pericytes, blood-borne, microglia); 4) progression of the process would be enhanced by the ability of microglial cells/macrophages to express Ia-antigens induced by the secretion of factors (INF- $\gamma$ ) by "activated" lymphocytes.

\section{ACKNOWLEDGMENTS}

This work was supported by the Department of Veteran Affairs Research Service, National Multiple Sclerosis Society, NASA cooperative agreement NCC2-449 with San Jose State University Foundation (F.E.D.),
NIH grant NS-11632 (Javits Neuroscience Investigator Award to L.F.E.), and NIH grant NS-02785 (Javits Neuroscience Investigator Award to M.E.S.). The authors extend their deep appreciation to Mrs. Rosemarie Binnard for excellent technical assistance in electron microscopy.

\section{REFERENCES}

Aquino D.A. Brosnan, C.F., Chiu, F.-C., and Norton, W.T. 11988a GFAP content GFAP content gradually increases up to 239 (Abstract \#3381.

cord. Trans. Am. Soc. Neurochem., 19.239 and Norton, W.T. (1988b) Aquino, D.A., Chiu, F.-C., Brosnan, C.F., and Norton, W.T. Glial fibriliary acidic protein incretoimmune encephalomyelitis. $J$ Neurochem., 51:1085-109.

Baron, M. and Gallego, A. (1972) The relation of the microglia with the pericytes in the cat cerebral cortex. Z. Zellforsch., 128:42-57.

cancilla, P.A. Baker, R.N., Pollock, P.S., and Frommes, S.P. (1972) The reaction of pericytes of the central nervous system to exogenous protein. Lab. Invest., 26:376-383.

Cragg, B.G. (1970) What is the signal for chromatolysis? Brain Res., $23: 1-21$

D'Amelio, F (1981) Silver impregnation techniques (del Rio Hortega) for normal and pathological nervous tissue. In: Current Trends in Morphological Techniques. J.E. Johnson, Jr., ed. CRC Press, Inc., Florida, pp. 145-186.

Florida, Pp. 145-186. and Smith, M.E. (1989) Dissociation of GFAP intermediate filaments in EAE: observations in the lumbar spinal cord. Glia 2:308-317.

For. LF and Rubinstein, L.J. (1978) Contribution of immunocytochemistry to diagnostic problems of human cerebral tumors. $J$. Histochem. Crtochem., 26:513-522.

Field, E.J. and Raine, C.S. (1966) Experimental allergic encephalomyelitis. Am. J. Pathol, 49:537-553.

Fontan mediated encephalitis: on the role of antigen-presenting cells in brain tissue. Immunological Rev., 100:185-201.

brain tissue. Immunological Ret. W.J., and Kreutzberg. G.11. 1988। ricroglial cells but not astrocites undergo mitosis following rat facial nerve axotomy. Neurosci. Lett. 85:317-321.

Imamoto, K and Leblond, C.P. (1978) Radioautographic investigation of gliogenesis in the corpus callosum of young rats. II. Origin of microglial cells. J. Comp. Neurol., 180:139-163.

microglial cells. J. Comp. Neurol... $O B$. (1984) Blood-brain and blood-spinal cord barrier permeability during the course of experimental allergic encephalomyelitis in the rat. Brain Res., 302:347-355.

Konno, H., Yamamoto, T., Iwasaki, Y., Saitoh. T., Suzuki. H., and Terunuma, H. (1989) la-expressing microglial cells in experimenta allergic encephalomyelitis in rats. Acta Neuropathol. 77:472-479.

allergic encephalomyelitis in rats. Acta Neurson, I.K. i 1963 i Radioautographic study of cellular mechanisms in delayed hypersensitivity tographic study of celluic encephalomyelitis in the rat. $J$. Nicuro. pathol. Exp. Neurol., 22:367-380.

parter under normal and pathological conditions. In: Histology and Histopathology of the pervous System. Vol. I. W. Haymaker and R. D. Adams, eds. Charles Thomas, Springfield, Illinois. pp. 798-890.

Thomas, spring Changes in the protein content of the spinal motor noure after severance of the axon. Nature, 196:837-838.

Miquel, J. Foncin J.F Gruner, J.E. and Lee, J.C. (1982) Cerebral ed edem. Haymaker and R. D. Adams, eds. Charles Thomas, Springfield. lilinois, pp. 871-919.

Oehmichen, M. (1975) Monocytic origin of microglia cells. In: Mononuclear Phagocytes in Immunity, Infection, and Pathology. R. van Furth, ed. Blackwell, pp. 223-240.

Pou M D Amelio, F Haymaker, W and Johnson, Jr. J. (1982) Polak, $M_{\text {.. D Amelio, }}$., Haymaker, In: Histology and HistopatholMicroglial cells: origins and reactions. W. Haymaker and R. D. Adams. ogy of the Nervous System, Vol. 1. W. Haymaker and $\mathrm{R}$. D. A

eds. Charles C. Thomas, Springfield, 1linois, pp. 481-55. distribucion regional de la microglia. Arch. Neurabiol. (Madridi. $2: 212-255$.

Rio Hortega, P. del (1932) Microglia. In: Cytology and Cellular Pathol. 
ogy of the Nervous System, Vol. 2. W. Penfield, ed. Hoeber, New York, pp. 481-534.

Roizin, L., Haymaker, W., and D'Amelio, F. (1982) Disease states involving the white matter of the central nervous system. In: Histol. ogy and Histopathology of the Nervous System, Vol. I. W. Haymaker and R.D. Adams, eds. Charles C. Thomas, Springfield, Illinois, pp. $1276-1489$.

Sobel, R.A., Natale, J.M., and Schneeberger, E.E. (1987) The immunopathology of acute experimental allergic encephalomyelitis. IV. An ultrastructural immunocytochemical study of class II major histocompatibility complex molecule (la) expression. J. Neuropathol. Exp. Neurol., 46:239-249.

Smith, M.E., Somera, F.P and Eng, L.F. (1983) Immunocytochemical staining for glial fibrillary acidic protein and the metabolism of cytoskeletal proteins in experimental allergic encephalomyelitis. Brain Res., 264:241-253.
Smith, M.E., Sommer, M.A., and Sadler, R.H. (1989) Antibodies to myelin constituents may regulate demyelination in EAE. J. Neurochem., 52 (suppl.), (Abstract).

Sternberger, L.A. (1986) Immunocytochemistry. John Wiley, New York.

Streit, W.J., Graeber, M.B., and Kreutzberg, G.W. (1988) Functional plasticity of microglia: A review. Glia, 1:301-307.

Streit, W.J. and Kreutzberg, G.W. (1988) Response of endogenous glial cells to motor neuron degeneration induced by toxic ricin. J. Comp. Neurol., 268:248-263.

Trotter, J. and Smith, M.E. (1984) Macrophage-mediated demyelination: the role of phospholipases and antibody. Prog. Clin. Biol. Res., 146:55-60. 